\title{
INCUBADORA E GESTÃO: UMA PERCEPÇÃO DAS EMPRESAS INCUBADAS
}

\author{
R. L. S. SILVA ${ }^{1,2}$, T. M. D'AMORE' ${ }^{1}$ A. G. ARAÚJO ${ }^{2}$ e M. L. S. S. SILVEIRA ${ }^{3}$ \\ 'Instituto Federal do Rio Grande do Norte - Campus São Gonçalo do Amarante, \\ ${ }^{2}$ Programa de Pós-Graduação em Administração - Universidade Federal do Rio Grande do Norte \\ ${ }^{3}$ Programa de Pós-Graduação em Engenharia de Produção - Universidade Federal do Rio Grande do Norte \\ renata.soares@ifrn.edu.br
}

\section{RESUMO}

O presente artigo compreende um estudo sobre a percepção das empresas incubadas em relação ao papel das incubadoras de empresas, especificamente a Incubadora Tecnológica Natal Central (ITNC) localizada no Instituto Federal do Rio Grande do Norte na cidade de Natal. Nesse sentido, esse trabalho tem por objetivo averiguar a representação social das empresas incubadas quanto ao suporte técnico e gerencial oferecido pela ITNC. O estudo foi construído a partir da Teoria das Representações Sociais e dos questionamentos que moveram Moscovici (1978) sobre a influência do campo comunicacional nas interações sociais. A metodologia escolhida foi a Associação Livre de Palavras, proposta por Abric (1994) aplicada aos empresários e funcionários das empresas incubadas, o que vem a corroborar com a teoria das Representações Sociais. Os resultados foram analisados a partir da Análise de Conteúdo proposta por Bardin (2004), permitindo apreender a representação que se estabelece entre as empresas incubadas e incubadora de empresas. Dessa forma, partindo dos resultados obtidos, propõe-se contribuir para o aprimoramento do programa de gestão da ITNC e, consequentemente, colaborar no inter-relacionamento entre as empresas incubadas e a incubadora de empresas, por meio das informações alcançadas através desse estudo.

PALAVRAS-CHAVE: Incubadora de Empresas, Gestão, Empresas Incubadas, Representação Social.

\section{INCUBATOR AND MANAGEMENT: A BUSINESS INCUBATOR VIEW}

\section{ABSTRACT}

This study investigates the perception view of start-ups companies in relation to the role of business incubators support, specifically Natal Central Technology Incubator (ITNC) located at the Federal Institute of Rio Grande do Norte in Natal city. Thus, it aims to assess the social representation of start-ups companies about the technical and managerial support provided by ITNC. This research was based on the Social Representations Theory Moscovici (1978). The methodology chosen was the Free Association of Words, proposed by Abric (1994) applied to business owners and employees of the startups companies, which corroborates with the Social Representation Theory. The results were analyzed based on content analysis proposed by Bardin (2004). Thus, based on the results, it is proposed to contribute to the improvement of the management program ITNC and thus collaborate in the interrelationship between the start-ups companies and business incubator, through the information accessed through this study.

KEYWORDS: Business Incubator, Management, Start-ups Companies, Social Representation. 


\section{INCUBADORA E GESTÃO: UMA PERCEPÇÃO DAS EMPRESAS INCUBADAS}

\section{INTRODUÇÃO}

O conhecimento, que sempre foi um dos principais insumos para a geração de riqueza e bem estar social, passou a ser reconhecido com advento da revolução da informação ocasionada pelas novas tecnologias indispensáveis para o desenvolvimento na atualidade. Para um país emergente como o Brasil, que busca caminhos para alcançar um nível de produção, renda e distribuição compatíveis com as necessidades da sociedade, investimentos em pesquisa de inovação tecnológica significa estar em sintonia no presente cenário de um mundo globalizado.

Entre as variadas iniciativas de políticas públicas de financiamento que visa a promoção de empreendedorismo, criação e desenvolvimento de novos empreendimentos, as incubadoras de empresas tem atraído bastante atenção (SCHWARTZ, 2008).

De acordo com ROCHA (2011), as primeiras incubadoras de empresas surgiram nos Estados Unidos no final da década de 30, alguns anos depois da quebra da Bolsa de Valores, a partir do trabalho de Hewlett e Packard, dois estudantes de Stanford, resultando posteriormente na criação da empresa global denominada HP, referência atual em tecnologia.

Nas últimas duas décadas houve um desenvolvimento tecnológico que, para Santos et al (2005) caracterizou um avanço significativo na produtividade devido à automação dos processos e à transferência e disponibilidade das informações. Esse desenvolvimento, segundo ROCHA (2011) possibilitou que o Brasil, no final da década de 90 alcançasse um crescimento significativo no que diz respeito ao quantitativo de incubadoras.

Nesse sentido, desempenhando um importante papel socioeconômico, com destaque para a geração de novos postos de trabalho, de renda e de novas unidades de negócios, o movimento de incubadora de empresas vem ampliando a demanda por recursos públicos, necessários à sua expansão e manutenção, o que passa a justificar estudos voltados a gestão da incubadora capazes de mensurar sua efetividade e sua capacidade de apoio à difusão de inovações (MUELLER; THOMAS, 2000, JACK; ANDERSON, 1999).

O propósito deste artigo é justamente reunir dados que situe o conceito de incubadora de empresas que segundo DIAS (2007), consiste em oferecer após o processo de nascimento de uma empresa, melhores condições de desenvolvimento e a consolidação sustentável de novos empreendimentos. Inicialmente, o presente estudo buscará apreender a representação que as empresas incubadas têm sobre o apoio fornecido pelas incubadoras de empresas, especificamente, a Incubadora Tecnológica Câmpus Natal Central (ITNC), situada no Instituo Federal de Educação, Ciência e Tecnologia do Rio Grande do Norte, foco da pesquisa.

A Incubadora Tecnológica do Câmpus Natal Central atua desde 1998 dando suporte ao surgimento de empresas de base tecnológica, principalmente, no âmbito de atuação das áreas afins da Instituição. Ao longo de quatorze anos de experiência graduou quinze empresas, tendo nos últimos cinco anos prospectados vinte projetos (PRIME - Programa Primeira Empresa Inovadora) e graduado seis empresas. O perfil das empresas incubadas ou em processo está relacionado a setores, tais como: confecções, comércio eletrônico, eletrônica e automação, geologia e mineração, geoprocessamento, tecnologia da informação e serviços especializados.

É pertinente ressaltar, que a ITNC está, atualmente, se preparando para o processo de certificação na metodologia CERNE - Centro de Referência para Apoio a Novos Empreendimentos - recém criado pela ANPROTEC - Associação Nacional de Entidades 
Promotoras de Empreendimentos Inovadores - que visa um melhor gerenciamento nas incubadoras de empresas, por meio da redução da variabilidade, ampliação da quantidade e qualidade dos empreendimentos, melhoria na transparência e padronização dos processos e ampliação da taxa de sucesso dos empreendimentos (ANPROTEC, 2012).

Esse novo cenário tem exigido que a ITNC se adeque aos novos modelos de negócios, uma vez que também servirá como referência de modelo de gestão às outras incubadoras presentes no estado do Rio Grande do Norte pertencentes ao IFRN. Recentemente, colocou em funcionamento em janeiro de 2011 a incubadora Tecnológica do Câmpus Mossoró, voltada ao segmento de Petróleo \& Gás Natural. E, em dezembro de 2011, pôs em funcionamento no câmpus de Currais Novos-RN a incubadora de tecnologia em melhoramento genético de bovinos leiteiros. Além disto, dentro da estratégia de auxiliar no desenvolvimento regional, foram lançadas mais quatro incubadoras, nos câmpus das cidades de Caicó (Tecnologia da Informação e Têxtil), Ipanguaçu (Agroecologia), João Câmara (Cooperativismo) e Pau-dos-Ferros (alimentos), nas suas respectivas áreas de atuação.

A presente pesquisa, ainda, justifica-se pela necessidade de se ampliar estudos com ênfase na gestão de incubadora de empresas que possibilite essas entidades atuarem com efetividade para a criação de empreendimentos inovadores. Percebe-se que há um esforço visando preencher a lacuna bibliográfica pertinente à avaliação da gestão de incubadoras empresariais. Entretanto, dados da Plataforma Scopus revelam que nos últimos cinco anos, apenas 63 (sessenta e três) trabalhos foram publicados com foco na avaliação de gestão da incubadora de empresas, enquanto que com ênfase nas empresas incubadas e suas características 262 (duzentos e sessenta e dois) foram apresentados.

Nesse cenário, pretende-se contribuir na busca de melhores condições de desenvolvimento e na consolidação sustentável de novos empreendimentos, por intermédio de uma gestão de incubadora mais eficaz e inovadora, que permita a sustentabilidade das empresas incubadas e da própria incubadora por meio da compreensão do papel que as incubadoras de empresas exercem quanto ao suporte técnico e gerencial do ponto de vista das empresas incubadas.

\section{ESTADO DA ARTE: INCUBADORA DE EMPRESAS}

O empreendedorismo é fundamental para o desenvolvimento sócio-econômico de um país/região, visto que é essencial para a concepção de oportunidades de trabalho e é considerado um catalisador do progresso tecnológico e de inovações de produto, serviços e de mercado (MUELLER; THOMAS, 2000), sendo empreendedorismo definido como "característica daquele que tem habilidade para criar, renovar, modificar, implementar e conduzir empreendimentos inovadores" (ANPROTEC, 2012).

Pesquisas internacionais recentes têm demonstrado a importância do estímulo ao empreendedorismo para o desenvolvimento da economia de um país. De acordo com Zhou e Jiang (2006) o estímulo ao empreendedorismo na China se deu a partir de 1978 quando o país experimentou uma abertura econômica orientada ao mercado. Corroborando com o pensamento destes autores, Fontes (2005) destaca o papel crucial que as micro e pequenas empresas na China tem desempenhado para o expressivo crescimento da economia nas últimas décadas. 
Já Dhar e Lyndall (1962) destacam o papel das micro e pequenas empresas como provedoras imediatas da larga geração de emprego na Índia. Segundo os autores, a Índia em 1962 publicou a resolução que define a política industrial do País, onde enfatiza a relevância dessas pequenas indústrias em ofertar uma melhor distribuição de renda na economia nacional, bem como o uso eficiente dos recursos de capital financeiro e humano que de outro modo estariam inutilizados.

De acordo com XI relatório da Global Entrepreneurship Monitor (GEM), maior estudo contínuo sobre a dinâmica empreendedora do mundo realizado em 2010, a taxa de Empreendedorismo em Estágio Inicial - TEA - proporção de pessoas na faixa etária entre 18 e 64 anos envolvidas em atividades empreendedoras na condição de empreendedores de negócios nascentes ou empreendedores à frente de negócios novos, ou seja, com menos de 42 (quarenta e dois) meses de existência - foi de $17,5 \%$ a maior taxa registrada desde que a pesquisa GEM é realizada no Brasil.

Ainda segundo o mesmo estudo, comparando os países do BRIC - Brasil, Rússia, Índia e China - o Brasil tem a população mais empreendedora, com $17,5 \%$ de empreendedores em estágio inicial, a China tem $14,4 \%$, a Rússia 3,9\%, enquanto a Índia não participou da pesquisa em 2010. Portanto, o que se observa é que o Brasil tem apresentado elevadas taxas de crescimento em números de negócios novos.

Entretanto, atualmente o cenário de micro e pequenas empresas tem se mostrado preocupante no País. De acordo com Marques (2006) as MPE'S são as maiores fontes geradoras de empregos diretos e indiretos, embora a realidade atual aponte um acesso deficiente às tecnologias, escassez de recursos financeiros e baseiam-se no conhecimento empírico para tomada de decisão. Os dados do SEBRAE/SP (2010) vem corroborar com essa afirmação. A pesquisa realizada por essa instituição registra a taxa de mortalidade das empresas nascentes brasileiras como maior que $49 \%$ no segundo ano, indo a quase $60 \%$ no quarto ano de vida de empresas.

Nesse contexto, o movimento de incubadoras de empresas tem assumido um papel estratégico no estímulo ao empreendedorismo no Brasil. De acordo com o Ministério da Ciência, Tecnologia e Inovação do Governo Federal, através do Programa Nacional de Apoio a Incubadoras de Empresas (PNI) (1998), incubadora de empresas consiste em um mecanismo que fomenta a criação e o desenvolvimento de micro e pequenas empresas (industriais, de prestação de serviços, de base tecnológica ou de manufaturas leves), oferecendo suporte técnico, gerencial e formação complementar ao empreendedor.

Corroborando com o Ministério da Ciência, Tecnologia e Inovação, Lingfang e Hongli (2010) asseveram que incubadoras de empresas oferecem um ambiente de recursos que podem ser compartilhados para atender as necessidades das empresas nascentes. Essas empresas, ao se incubarem e permanecerem certo tempo desenvolvendo seus negócios, e tão logo se tornem negócios maduros formam um empreendimento competitivo, capaz de concorrer no mercado.

Dessa maneira, ao fornecer recursos e serviços em um só lugar permitindo redução de custos no compartilhamento das instalações, as incubadoras de empresas são focadas para melhorar significativamente a sobrevivência e as perspectivas de crescimento das pequenas empresas em um estágio inicial de desenvolvimento (BOLLINGTOFT, 2012). 
De acordo com Mian (1996), o conceito de incubação procura vincular, efetivamente, talento, tecnologia, capital e conhecimento para alavancar o talento empresarial, acelerar o desenvolvimento de novas empresas, e assim acelerar a comercialização de tecnologia.

No que diz respeito à visão estratégica no longo prazo, a Incubadora de empresa visa à ampliação da competitividade de micro e pequenos empreendedores locais, com ênfase no desenvolvimento regional. Dornelas (2002) define incubadora de empresas como um ambiente flexível e encorajador com facilidades para o surgimento e o crescimento de novos empreendimentos. Corroborando com o pensamento do autor, Grimaldi e Grandi (2005) reafirma que o conceito de incubação busca um meio eficaz de ligar o capital, a tecnologia e o conhecimento a fim de alavancar talento empreendedor, acelerar o desenvolvimento de novo empresas e, portanto, acelerar a exploração da tecnologia.

É lícito dizer, que as incubadoras de empresas estão localizadas próximas as universidades ou instituições geradoras de conhecimento, o que possibilita acesso à infraestrutura e aos recursos humanos dessas instituições (LAHORGUE; HANEFELD, 2004, JABBOR; DIAS; FONSECA, 2004). Com efeito, a importância das Incubadoras está intimamente relacionada com 0 desenvolvimento sustentável que delas resulta devido à sua capacidade de transformar os resultados da ciência em novas tecnologias inovadoras, especialmente quando se combinam competências acadêmicas e empresariais.

Portanto, um olhar criterioso para a gestão inserida no ambiente da incubadora, que possibilite a concretização dos objetivos propostos por essas entidades provedoras de empreendimentos inovadores, tem demonstrado como essencial, visto o aumento considerável do numero de incubadoras de empresas no País.

\section{METODOLOGIA}

$\mathrm{Na}$ condução da pesquisa desenvolvida, foi utilizada como metodologia a técnica da Associação Livre de Palavras, método proposto por Abric (1994, p. 66) que considera como "uma técnica maior para coletar os elementos constitutivos do conteúdo de uma representação", aplicada com os empresários e os funcionários das empresas incubadas, no sentido de conhecer a subjetividade dos mesmos e, ainda, pelo caráter espontâneo do teste e sua dimensão projetiva permitir o acesso ao universo semântico dos termos implícitos ou latentes, que poderiam estar mascarados em produções discursivas.

Moscovici (1978) considera a comunicação como parte dos estudos das representações sociais. Seus trabalhos marcam bem este postulado, visto que estabelecem justamente a relação entre estes dois campos, relação esta apresentada no próprio conceito de representações sociais formulado por ele: "Uma representação fala tanto quanto mostra, comunica tanto quanto exprime [...] é uma modalidade de conhecimento particular que tem por função a elaboração de comportamentos e a comunicação entre indivíduos" (MOSCOVICI, 1978, p.27).

A técnica da Associação Livre de Palavras foi realizada em cada empresa com os empresários e funcionários, dia após dia, atingindo o total de oito pessoas, nas oito empresas incubadas. Segue-se a descrição das empresas incubadas, de acordo com o quadro 01 a seguir. 
Quadro 01 - Caracterização das Empresas Incubadas

\begin{tabular}{|c|c|l|c|}
\hline Nome & Setor & \multicolumn{1}{|c|}{ Produtos } & $\begin{array}{c}\text { Tempo de Incubação } \\
\text { (meses) }\end{array}$ \\
\hline A & Serviços & Desenvolvimento de Softwares & 35 \\
\hline B & Serviços & Jogos Digitais & 35 \\
\hline C & Serviços & Sistema de NF-e & 35 \\
\hline D & Serviços & Software Administrativo & 4 \\
\hline E & Serviços & Camisetas Criativas & 47 \\
\hline F & Serviços & Sistemas de Controle de & 35 \\
\hline G & Serviços & Softwacionamentos & 6 \\
\hline H & Serviços & Publicidade Gestão & 47 \\
\hline
\end{tabular}

O perfil das empresas incubadas da ITNC apresenta sob o ponto de vista do tempo de incubação, uma média de 30,5 meses. Todas voltadas para o setor de serviços, com foco na área da tecnologia da informação.

Após o estabelecimento das empresas incubadas, definiu-se duas palavras como indutora/estímulo: INCUBADORA e GESTÃO. Na ocasião, foi solicitado aos profissionais que dissessem as três palavras que lhes vinham prontamente à mente, quando fosse falado as palavras incubadora e gestão, e quais as que consideravam mais importantes, justificando a sua opinião.

Para tanto, utilizou-se a Análise de Conteúdo (Bardin, 2004) empreendida para a compreensão das justificativas para formação dos grupos de palavras, pelos participantes. Essa análise promove o acesso ao sistema e categorias conceituais dos sujeitos. Para realização da Análise de Conteúdo, partiu-se das falas dos empresários e funcionários com o intuito de aferir sobre os conhecimentos relativos ao campo representacional de incubadora e gestão e como seus sentidos são apreendidos pelos profissionais das empresas incubadas. Adotou-se nesse estudo a definição de Bardin de Análise de Conteúdo:

[...] a análise de conteúdo aparece como um conjunto de técnicas de análise das comunicações, que utiliza procedimentos sistemáticos e objetivos de descrição do conteúdo das mensagens (BARDIN, 2004, p.33)

Dentre as técnicas da análise de conteúdo trabalhou-se com análise categorial. A categorização segue critérios pré-estabelecidos. Nesse estudo, adotou-se o critério semântico, trabalhando com a análise temática, investigando os núcleos de sentido que constituem a comunicação através de temas. É a forma de categorização mais adequada ao corpus desse estudo, uma vez que se aplica a discursos diretos e simples e ao estudo de motivação de atitudes, de representação, de valores, de crença, etc. (Bardin, 2004).

Por tema entende-se uma unidade de significação, cujos tamanhos e limites não correspondem necessariamente à extensão de frase(s) ou parágrafo(s). Isto é, o que determina um tema não são correspondentes lingüísticos, mas asserções que tratam de um mesmo tópico de sentido ( Bardin, 2004). 
Com base na análise temática, buscou-se os temas nas justificativas dos empresários e funcionários, e, em seguida, formou-se as categorias diferenciando ou agregando esses temas a partir de sentidos.

De acordo com Franco (1986) a objetividade das análises empreendidas, decorre da interação ativa entre o conteúdo manifesto e explícito de uma comunicação e o sistema interpretativo do pesquisador.

\section{APRESENTAÇÃO E ANÁLISE DOS RESULTADOS}

O papel que as Incubadoras de Empresas exercem é fundamental na disseminação da cultura empreendedora e para o fortalecimento gerencial das empresas incubadas. A partir dessa observação, constata-se na presente pesquisa que as empresas incubadas percebem a importância do papel da incubadora de empresa como fonte geradora de suporte técnico e gerencial, bem como apoio em gestão e planejamento.

A técnica da associação livre de palavras, pelo caráter espontâneo, permitiu recolher elementos constitutivos dos sentidos atribuídos a "Incubadora" e "Gestão" presentes nos discursos de empresários e funcionários. Examinar os sentidos atribuídos à Incubadora e à Gestão com a finalidade de apreender a subjetividade dos funcionários e empresários aliado, ainda, pelo contexto da temporalidade, anteriormente observado no quadro 01, da ausência de critérios que determine o tempo de graduação das empresas incubadas que apresentam, nesse estudo uma média de 30,5 meses, demonstra a importância da presente pesquisa.

A correspondência dos critérios, categorias e frequência harmonicamente relacionados constituem um indicador da centralidade dos elementos que condensam os conteúdos mais próximos da percepção de empresários e funcionários na avaliação.

Inicialmente, apresenta-se a figura 01 que contém a categorização das evocações e as frequências da palavra INCUBADORA como estímulo indutor da percepção dos empresários e funcionários das empresas incubadas.

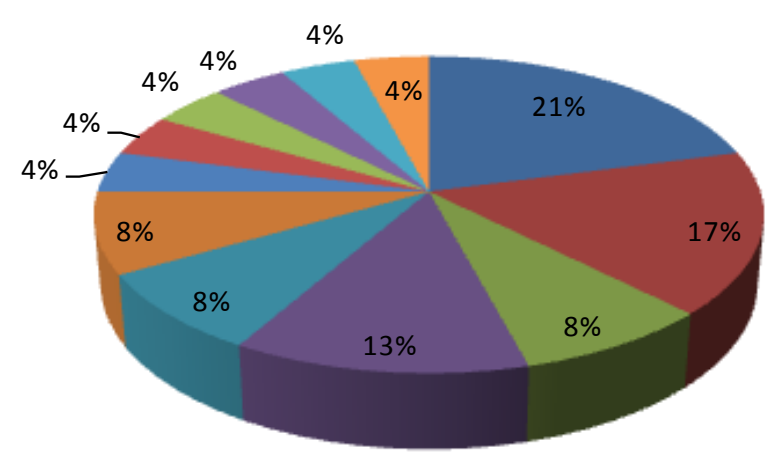

$$
\begin{aligned}
& \text { - Apoio } \\
& \text { - Início } \\
& \text { - Suporte } \\
& \text { - Assistência } \\
& \text { - Ajuda } \\
& \text { - Oportunidade } \\
& \text { - Qualificação } \\
& \text { - Investimento } \\
& \text { - Conforto } \\
& \text { - Aprendizagem }
\end{aligned}
$$

Figura 1: Categoria e Frequência das palavras evocadas no estímulo incubadora.

A interpretação dos dados das evocações dos empresários e funcionários, com a palavra indutora Incubadora, possibilitou-se observar como está relacionada à quantidade de freqüência 
e evocações, que na categoria APOIO, é mais relevante e mais representativa, pelo entendimento lógico da subjetividade dos empresários e funcionários manifestado no conteúdo das evocações.

É pertinente ainda, com base nos resultados observados, inferir que os elementos constituintes da representação Incubadora são:

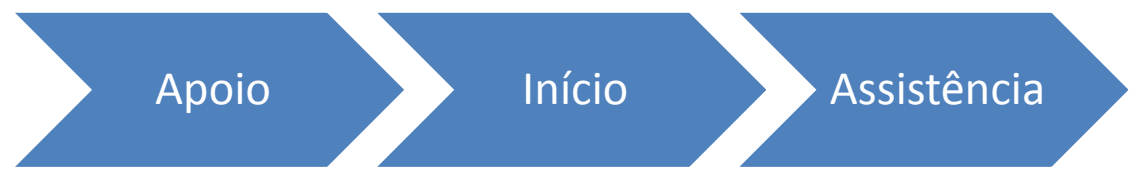

Essas observações são pertinentes ainda, pela justificativa atribuída aos referidos vocábulos presentes nos depoimentos dos empresários e funcionários:

"apoiar é a função da incubadora, proporcionando tranquilidade para empresa que inicia"

"Porque acho que é o que cabe melhor a incubadora é início"

"Assistência! Acho que as empresas incubadas ainda enfrentam dificuldade de assistência, apoio".

Apresenta-se a seguir, a figura 02 que contém a categorização das palavras evocadas e as frequências da palavra GESTÃO, como estímulo indutor da representação dos empresários e funcionários das empresas incubadas. A palavra ADMINISTRAÇÃO representa a categoria Gestão de forma mais relevante, apontada nas falas dos empresários e funcionários quando justificam as evocações representadas. Como exemplo:

"Porque conhecimento técnico todos nós temos, mas não sabemos definir o preço do nosso produto nem sua comercialização, ou seja, administrar."

"Porque acredito que a administração é, hoje, a principal ferramenta de melhoria empresarial, principalmente como uma ferramenta de gestão."

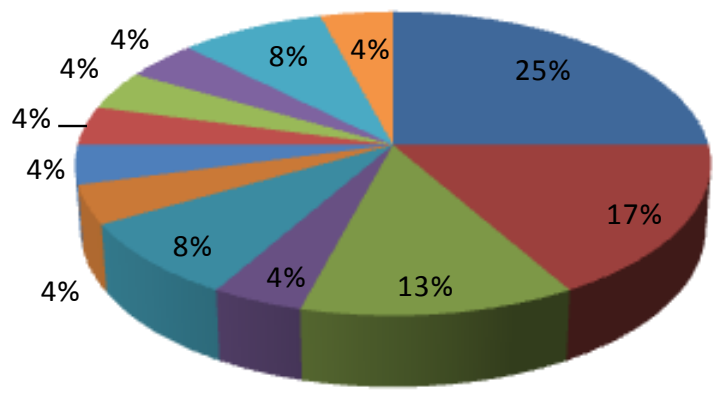

$$
\begin{aligned}
& \text { - Administração } \\
& \text { - Organização } \\
& \text { - Controle } \\
& \text { - Eficiência } \\
& \text { - Planejamento } \\
& \text { - Essencial } \\
& \text { - Indicadores } \\
& \text { - Treinamento } \\
& \text { - Divisão do Trabalho } \\
& \text { - Responsabilidade } \\
& \text { - Gerenciamento } \\
& \text { Dinheiro }
\end{aligned}
$$

Figura 2: Categoria e Frequência das palavras evocadas no estímulo gestão 
De acordo com a figura 2, Gestão é:

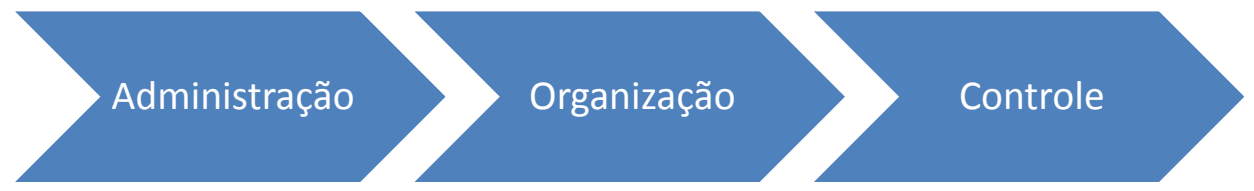

Pode-se aferir que as frequências das duas categorias APOIO e ADMINISTRAÇÃO são percentualmente próximas, o que proporciona contemplar que pequenas empresas nascentes, necessitam no início de mecanismos que potencializem e estimulem a sua criação em um ambiente flexível e encorajador, facilitadores para o crescimento de novos empreendimentos. Ou seja, as incubadoras empresariais precisam desempenhar atribuições que, ao mesmo tempo, as tornem instrumentos catalisadores e fomentadores do sucesso de novos empreendimentos e inovações.

Essa constatação se aproxima das falas dos empresários e funcionários onde se evidencia a consciência que estes profissionais tem em relação ao apoio inicial estabelecido no contexto administrativo das incubadoras de empresas. Entretanto, faz-se necessário um olhar mais atento para a gestão da incubadora de empresas - ITCNC, pela relevância que tem no fomento à inovação das empresas incubadas no âmbito do Rio Grande do Norte.

É oportuno ressaltar, que em detrimento da falta de acompanhamento e monitoramento efetivo de uma equipe de gestão da própria incubadora, detectado por meio da subjetividade dos discursos, as empresas incubadas percebem certa vulnerabilidade no apoio exercido pela ITCNC.

Finalmente, a relação dialética entre incubadora e gestão, esquematizada abaixo, figurase como um aspecto essencial no propósito básico da existência de uma incubadora de empresas, afinal, parafraseando o poeta e compositor Caetano Veloso "é preciso estar atento e forte, é preciso não temer a morte", objeto do desejo e da luta de todo empreendedor que necessita do suporte de uma administração efetiva para NASCER, dia após dia, em um mercado estrategicamente competitivo.
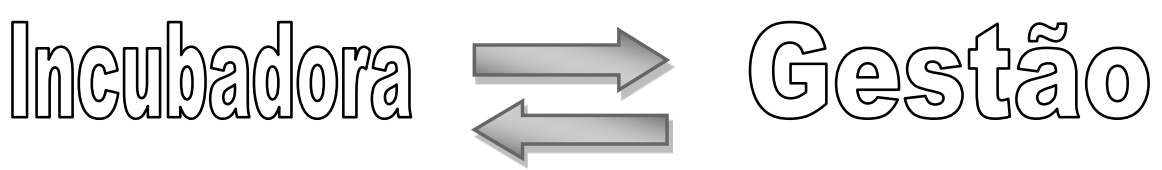

\section{CONSIDERAÇÕES FINAIS}

Sabe-se que nada é definitivo, conceitos são mudados a cada instante e novas descobertas surgem embaladas pelo movente mundo social que cria e se recria a cada instante. $\mathrm{E}$ são esses novos desafios que movem o mundo acadêmico. Como bem diz o sábio provérbio chinês: não há fim para o estudo. 
Esse estudo teve como propósito principal averiguar a representação social das empresas incubadas quanto ao suporte técnico e gerencial oferecido pela ITNC.

O pressuposto que embasou esse estudo foi o fato de que o programa de incubação de empresas no país tem passado por um processo de expansão quantitativa, tornando-se valioso investigar a qualidade da gestão interna da incubadora do ponto de vista das empresas incubadas. Aliado a isso, a possibilidade da certificação das incubadoras de empresas na metodologia CERNE exige que essas entidades adequem seus processos a uma gestão eficiente que comungue com os requisitos gerenciais.

Os resultados da pesquisa demonstram que os empresários e funcionários das empresas incubadas tem consciência do papel da ITNC para o apoio inicial dos negócios nascentes vinculado ao contexto administrativo da própria gestão da incubadora. Na subjetividade dos discursos, concluiu-se que as empresas incubadas se sentem vulneráveis acerca do apoio recebido pela incubadora, dificultando o fortalecimento sustentável desses empreendimentos e consequentemente o alcance da maturidade gerencial.

Entende-se que os resultados encontrados podem ser explicados pelo conteúdo dos significados atribuídos à questão ao longo desse estudo, sendo refletivo, inclusive pela falta de regularidade do tempo de incubação das empresas incubadas. Ainda, a partir dessa observação, verifica-se que os significados apresentados pelas empresas incubadas demonstram a utilização das Incubadoras como um lugar seguro para empreender, permitindo ao empreendedor a obtenção das citadas competências (apoio e administração) em busca de resultados positivos para seu negócio, como por exemplo: o aumento do ciclo de vida das suas empresas, ampliação da interação com o setor empresarial, com as Universidades e na otimização da aplicação de recursos.

Finalmente, a pretensão desse estudo foi contribuir na luta em prol do estímulo a criação de empreendimentos inovadores, embora seja reconhecido que muitas questões ainda necessitam de estudos mais aprofundados e suas possíveis implicações no que diz respeito à construção e reconstrução da ótica da gestão de incubadora de empresas. Portanto, é necessário um novo olhar.

\section{REFERÊNCIAS BIBLIOGRÁFICAS}

1. ABRIC, J.C. Pratiques sociales et reprèsentations. Paris: Presses Universitaires de France, 1994.

2. ANPROTEC - Associação Nacional de Entidades Promotoras de Empreendimentos de Tecnologias Avançadas. Site: http://www.anprotec.org.br. Acesso em 20.05.2012

3. BARDIN, L. Análise de Conteúdo. Tradução Luis Antero Reto e Augusto Pinheiro, 3 ed. Lisboa: Edições 70, 2004.

4. BOLLINGTOFT, A. The bottom-up business incubator: Leverage to networking and cooperation practices in a self-generated, entrepreneurial-enabled environment. Technovation, Volume 32, Issue 5, May 2012, 304-315.

5. DIAS, D. C. A Importância das Incubadoras de Empresas no Processo de Inovação nas Empresas de Base Tecnológica - O Caso da Incubadora de Empresas de Base Tecnológica CENTEV/UFV, 2007. 
6. DHAR, P e LYDALL, $H$. The role of small enterprises in Indian economy, The journal of Asian studies, 1962.

7. DORNELAS, J.C.A.. Planejando incubadora de empresas: como desenvolver um plano de negócios para incubadoras. Rio de Janeiro: Campus, 2002.

8. FONTES, W. Small and medium enterprises financing in China, Universitat Pompeu Fabra Press, 2005.

9. FRANCO, M.L.P. O que é análise de conteúdo. Caderno do programa de estudos de pósgraduação em pscicologia educacional da PUC-SP, São Paulo, n.7, 1986.

10. GRIMALDI, R.; GRANDI, A. Business incubators and new venture creation: an assessment of incubating models. Technovation, 25 (2005) 111-121.

11. JABBOUR, J. C.; DIAS, P. R.; FONSECA, S. A. As incubadoras de empresas como redes empresariais pró-inovação. Revista FEB/UNESP. http://revista.feb.unesp.br, 2004.

12. JACK, S.L.; ANDERSON, A.R. Entrepreneurship education within the enterprise culture. International Journal of Entrepreneurial Behaviour \& Research. Vol. 5 No 3, p. 110-125, 1999.

13. LAHORGUE, M.L e HANEFELD, A.O. A Localização das Incubadoras Tecnológicas no Brasil: Reforço ou quebra da tendência histórica de concentração das infra-estruturas de ciência, tecnologia e inovação, 2004.

14. LINGFANG, L. e HONGLI, L. Modeling and Measuring Intellectual Capital of Business Incubator. Proceedings - 3rd International Conference on Information Management, Innovation Management and Industrial Engineering, ICIII 20104 , art. no. 5694852 , pp. 79-82, 2010.

15. MARQUES, A. A logística como fonte de vantagem competitiva nas micro e pequenas empresas. São Paulo: SIMPEP, 2006.

16. $\mathrm{MCTI}$ - Manual para a Implantação de Incubadora de Empresas. Secretaria de Desenvolvimento Tecnológico. Brasília, 1998.

17. MIAN, S. A. Assessing value-added contributions of university technology business incubators to tenant firms. Research Policy 25 (1996) 325-335.

18. MOSCOVICI, S. A representação social da psicanálise. Tradução Álvaro Cabral. Rio de Janeiro: Zahar Editora, 1978.

19. MUELLER, S.L.; THOMAS, A.S. Culture and entrepreneurial potential: a nine country study of locus of control and innovativeness. Journal of Business Venturing, Vol.16, p. 5175, 2000.

20. ROCHA, A. Incubadoras de Empresas - Do surgimento no cenário mundial à inserção no Brasil. Administradores, 2011. Site: http://www.administradores.com.br/producaoacademica/incubadoras-de-empresas-do-surgimento-no-cenario-mundial-a-insercao-nobrasil/3762/ acesso em 19.06.2012.

21. SANTOS, J. P; LEITE, J. Y. P; ARAÚJO, A. L. C. A. Empreendedorismo e Inovação Tecnológica - uma nova metodologia. Holos, Ano 21, 2005.

22. SCHWARTZ, M. Incubator Age and Incubation Time: Determinants of Firm Survival after Graduation? Halle Institute for Economic Research $N \circ 14,2008$.

23. SEBRAE-SP, MPE's de Base Tecnológica: conceituação, formas de financiamento e análise de casos brasileiros. São Paulo, 2010.

24. ZHOU, C. e JIANG, F. China's Small Enterprises in Economic Transition: Successes and Problems, Indian Journal of Economics \& Business, Special Issue China, 2006. 